\title{
The political imaginaries of blockchain projects: discerning the expressions of an emerging ecosystem
}

\author{
Syed Omer Husain ${ }^{1}\left[\right.$ ] Alex Franklin² Dirk Roep $^{3}[$
}

Received: 14 August 2019 / Accepted: 7 February 2020 / Published online: 26 February 2020

(c) The Author(s) 2020

\begin{abstract}
There is a wealth of information, hype around, and research into blockchain's 'disruptive' and 'transformative' potential concerning every industry. However, there is an absence of scholarly attention given to identifying and analyzing the political premises and consequences of blockchain projects. Through digital ethnography and participatory action research, this article shows how blockchain experiments personify 'prefigurative politics' by design: they embody the politics and power structures which they want to enable in society. By showing how these prefigurative embodiments are informed and determined by the underlying political imaginaries, the article proposes a basic typology of blockchain projects. Furthermore, it outlines a frame to question, cluster, and analyze the expressions of political imaginaries intrinsic to the design and operationalization of blockchain projects on three analytic levels: users, intermediaries, and institutions.
\end{abstract}

Keywords Blockchain $\cdot$ Political imaginaries $\cdot$ Prefigurative politics $\cdot$ Decentralization $\cdot$ Technopolitics

\section{Introduction: why question the political imaginaries under-pinning technical infrastructures?}

Until 2013, much excitement revolved around Bitcoin, the Cryptocurrency (CC) which introduced online distributed ledgers to the world; from then on, attention shifted to the

Handled by L.G. Horlings, Spatial Planning and Environment, Netherlands.

Syed Omer Husain

syedomer.husain@wur.nl

Alex Franklin

ac0569@ coventry.ac.uk

Dirk Roep

dirk.roep@wur.nl

1 Rural Sociology Group, Wageningen University, Room 3022, Hollandseweg 1, 6706 KN Wageningen, The Netherlands

2 Centre for Agroecology, Water and Resilience, Coventry University, Wolston Ln, Ryton-on-Dunsmore, Coventry CV8 3LG, UK

3 Rural Sociology Group, Wageningen University, Room 3019, Hollandseweg 1, 6706 KN Wageningen, The Netherlands vast potential applications of the ledger itself, popularly referred to as blockchain. ${ }^{1}$ Academic studies, popular and social media, slack and GitHub forums, MeetUps, Ted Talks, blogs, conference keynotes, and white papers surrounding blockchain variously show the vast diversity of opinions, visions, and prescriptions surrounding the technology. Everything within a spectrum from blockchain as having "the potential for reconfiguring all human activity" (Swan 2015, p. viii) to it being a "useless" technology and a scam (Aslam 2018) can be found effortlessly. To add to this, the hype surrounding blockchain's transformative or disruptive potential is fueled by a diversity of actors; including technologists, governments, businesses, banks, start-up entrepreneurs, coders, hackers, anarchists, ecologists, and international organizations-all of whom are experimenting with the technology for different purposes. Hence, the starting point of this article is the scholarly and pragmatic need for navigating the widely prevalent techno-utopianism and techno-cynicism on the topic.

Put simply, blockchain is a shared cryptographic register. It records transactions between two parties in a permanent and verifiable manner without the need for any intermediary

\footnotetext{
${ }^{1}$ Blockchain is often conflated with distributed ledger technology (DLT). In brief, blockchain is only a 'type' of DLT. For clarifications, refer to: (Banco Bilbao Vizcaya Argentaria 2019).
} 
or central authority. Though blockchains themselves can be seen as a development that drew from and combined many existing technologies (Campbell-Verduyn 2017), in this article, we situate them as the meeting point of two historical trajectories: the ledger (Peters and Panayi 2016) and the Internet. We mention this to elucidate a simple point: the historical evolution of any general-purpose technology like the ledger, or the Internet, comes with diverse sets of political under-pinnings, or political imaginaries (McBride 2006; Nowotny 2014, p. 17), that play out in many different ways-some more dominant than others. For instance, amongst other developments, the ledger enabled the formation of a credit system to speed up the exchange of goods and services, which defined the expansion of power and wealth in societies (Gleeson-White 2011). The Internet decentralized communication and knowledge by creating networks of computers that would enable people to send information directly to each other (Gupta 2017; Tabora 2018). While the Internet has been used for raising awareness about and organizing around global issues like climate change and poverty, it has also been used by the behemoths of transnational banking to create debt and associated financial crises. Groups with different political imaginaries make and use technology in different ways.

In this article, a political imaginary is conceptualized as "a collective structure that organizes the imagination and the symbolism of the political, and therefore, organizes the instituting process of the political as well" (Browne and Diehl 2019 , p. 394). This definition follows from Taylor's work on social imaginaries, expounding how our shared political, economic, and social practices are framed by an exercise in collective imagining regarding their purpose and relevance. This exercise creates a "common understanding that makes possible common practices and a widely shared sense of legitimacy" (Taylor 2004, p. 23). According to some, the political is changing shape, and being determined by hybrid combinations of old ideologies (Grant 2014; Nowotny 2014; Wilson and Swyngedouw 2015) and leading to a loss of political agency and repression of the political (Mouffe 2005; Beveridge and Koch 2017). Furthermore, there are emerging technologies like blockchain enabling new forms of political experiences - both online and offline-influencing the collective imagination of the political. Considering the dramatic changes to the nature of the political itself, the traditional concepts from political science, sociology, and related disciplines "have difficulty in explaining how the political is constituted" (Browne and Diehl 2019, p. 393), let alone incorporating an analysis of techno-political innovations like blockchain.
To that end, we show how blockchain projects personify 'prefigurative politics' ${ }^{2}$ by design - the idea that their technical and organizational forms, to a large extent, embody the political imaginaries and power structures which they want to enable in society. Generally, the themes of decentralization of power, disintermediation from longstanding intermediaries like government and banks, and cryptographically enhanced transparency, dominate the blockchain discourse (Tapscott and Tapscott 2016). In spite of the inherently political nature of these technologies, most of the early studies largely evaded discussing the broader, longer term socio-political implications that various projects would have on society, governance, and politics (Atzori 2015). Legal scholarship "detailed the varied manners in which Bitcoin, $\mathrm{CCs}$, and blockchains fit within existing formal laws and regulations often loses sight of the wider governance implications" (Campbell-Verduyn 2017, p. 4). ${ }^{3}$ Computer science studies focused on experimenting with different technical infrastructures and features (Herbert and Litchfield 2015; Huckle et al. 2016; Liang et al. 2017). Economists fixated their analyses on cryptocurrencies, cost efficiencies, initial coin offerings (ICOs), and their progress (O'Dwyer 2015; Böhme et al. 2015; Catalini and Gans 2016; Conley 2017). While there are a number of recently published overviews highlighting various research directions required in the field (Risius and Spohrer 2017; White 2017; Ferreira et al. 2019; Casino et al. 2019; Mackey et al. 2019; Treiblmaier 2019; Tang et al. 2019; Lu 2019), excluding a handful of studies, ${ }^{4}$ in-depth research about the political consequences of blockchain projects is absent to date.

In response to this state-of-play in the blockchain research space, this paper aims to advance a clear agenda for further research politicizing the imaginaries underlying a range of blockchain projects. We assert that analyzing the political imaginaries of the so-called 'game-changing', general-purpose technologies are vital, since it determines the types of socio-economic and political actions that can emerge from, within, or on these interfaces. Exercises and debates in political imagination of emerging techno-political systems will thus, not only help us identify and cluster the political

\footnotetext{
$\overline{2}$ According to Graeber, "the idea that the organizational form that an activist group takes should embody the kind of society we wish to create" Explanation has been adapted from: (Graeber 2013, p. 23) For more information of prefigurative politics/prefiguration, please refer to (Murray 2014; Scott 2015; Yates 2015; Baker 2016; Gordon 2018).

3 The citation comprises of the following additional references: (Middlebrook and Hughes 2013; Farmer 2014; Bollen 2016).

${ }^{4}$ Indeed, this is not an exhaustive list of citations-but scholarly literature in development and social impact studies take another stance mostly conceptualizing how a particular project could (often hypothetically) enable a fairer society (Atzori 2015; De Filippi and Loveluck 2016; Campbell-Verduyn 2017; Herian 2018).
} 
trends of current projects, but also develop normative arguments for and against design features of future projects. In other words, it is only this sort of rigorous political analysis that could potentially open up blockchain projects, as well as other techno-political innovations to other, alternative imaginations. Furthermore, we follow many others in taking the stance that technology is neither neutral nor apolitical in its technical design or socio-economic implementation (Strate 2012; Scott 2015). On the contrary, we attempt to show how blockchain projects contain different in-built features of access, decision-making, and value-all of which influence power relations between individuals and communities. The main intention of this paper is to provide a starting point to identify, cluster, and analyze the underlying political imaginaries of blockchain projects and set up a corresponding research agenda to stimulate further inquiry. It does so by creating a basic typology of blockchain projects (Table 1), as well as a frame (Table 2) through which the expressions of project-specific political imaginaries can be analyzed. We advocate a more collaborative approach to designing and conceptualizing these technologies, where academics, technologists, policymakers, and lawyers work together. Considering the wealth, diversity, and speed at which blockchain initiatives are being created, we emphasize the urgency of articulating a broader, more multidisciplinary approach that rigorously questions the possible political implications.

The article proceeds as follows. Having foregrounded the idea of imaginaries and their prefigurative embodiments, we supplement the analytical frame by drawing on concepts from transition theory and critical geography. After proposing a basic typology of four basic clusters of projects based on their political imaginaries, we reflect on the tensions, myths, and pathologies surrounding blockchain's oft-cited design principles and how to approach them from a political imaginary perspective. We then advance a preliminary frame which identifies expressions and implications of political imaginaries on three analytic levels; users, intermediaries, and institutions.

\section{Framing the issue: transformation, creative destruction, and prefigurative politics}

To understand how to open up blockchain projects to other political imaginations, we must also conceptualize our agency and control over technological evolution. Framed differently, to what extent do the technologies themselves shape their evolution through path-dependent technological logic? (Dafoe 2015, p. 1048). Until the 1980s, a widely accepted stance was that technological evolutions is an autonomous history-shaping process (Carpenter and Winner 1978). It followed an internal logic and progression, which had a life of its own and premised societal structures without

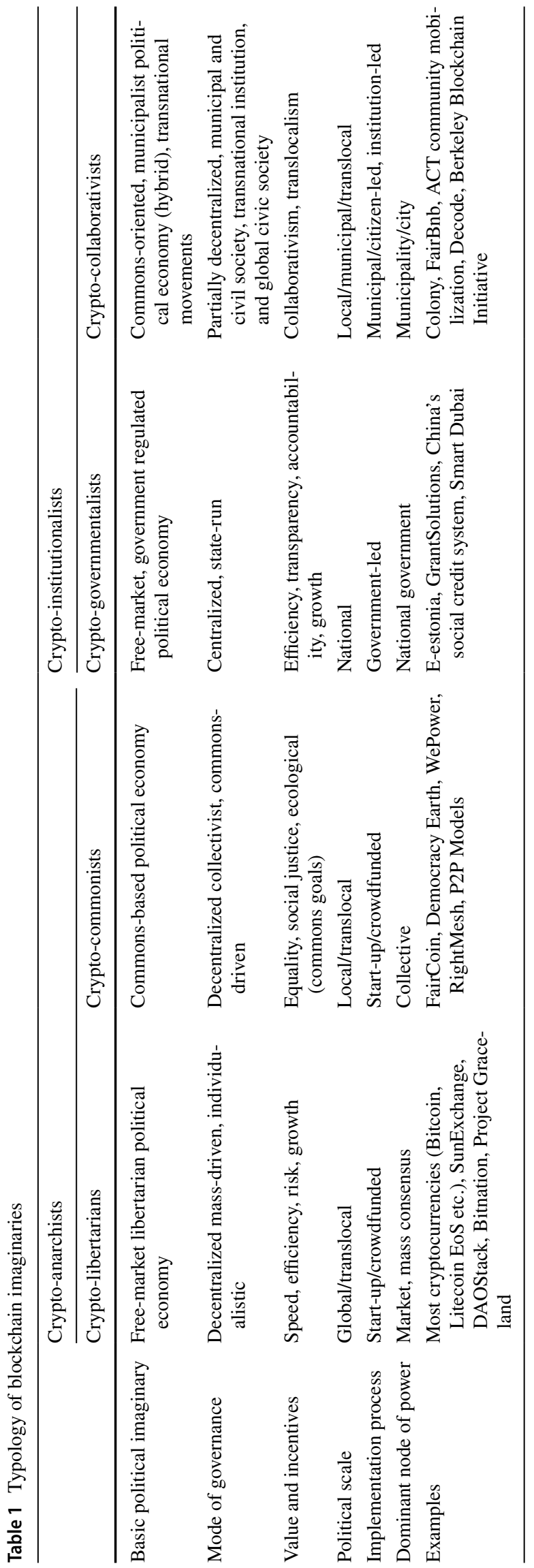


human intentionality (Kelly 2010). Even though this sort of technological determinism was dismissed by subsequent constructivist claims which highlighted the role of social groups, contexts, and other perceptions of meaning (Hackett et al. 2008; Lynch 2008; Kline 2015), the corresponding "effects and autonomy of technology are neglected" (Dafoe 2015, p. 1049). This neglection, in turn, shows up in the widely prevalent polarized perspectives in the blockchain space in general: techno-utopianism (Tapscott and Tapscott 2016; Kshetri 2017; Radziwill 2018; Brody 2019) and techno-cynicism (De Filippi and Loveluck 2016; Golumbia 2016; Ian Bogost 2017; Volmar 2017; Roubini 2018). It also shows up in the lack of frames understand the potential socio-politically transformative effect technology (in this case, blockchain projects) has on society.

Though most books and studies on blockchain often refer to its transformative or disruptive potential (Tapscott and Tapscott 2016; Radziwill 2018; Saberi et al. 2018a), there is little understanding of what that actually implies from a political point of view (Atzori 2018). Without identifying and conceptualizing this potential with regards to our agency, it is impossible to open up techno-political evolution to achieving any transformation that leads to a more equitable political system. This involves asking questions such as: are the imaginaries informing blockchain open or flexible enough to be changed?; How 'active' was the construction of these imaginaries in the initial instance?; do blockchain practitioners consciously realize the political imaginaries their tech embodies? In the following, these questions help open up and guide the research agenda about political imaginaries and their embodiment in blockchain projects. However, we acknowledge that choosing concepts to frame the discussion is in itself a normative exercise and leads to some implicit prioritization of types of transformation. The concepts and frameworks below were chosen on the basis of their ability to help critically explain the construction and practice of techno-political transformation to create a more equitable system of politics.

Swartz (2016) identifies two types of blockchain projects: radical and incorporative. Simply put, radical projects are oriented towards revolutionary social, economic, and political changes through imagining a new techno-political order. These systems enable users to circumvent the dominant institutional setting - central governments, banks, and corporations-by creating new ones. Contrastingly, incorporative projects innovate within the existing techno-political system not (necessarily) aiming for a reconstruction of the underlying political and social premises, but instead providing, for instance, more transparency and autonomy (Swartz 2016, pp. 86-87). As she clarifies, "the distinction...is not clearly defined and, in practice, there is a continuum between the two ideological modes" (Swartz 2016, p. 87). Often, we see how many radical start-ups which begin with "utopian visions might 'pivot' (to use industry parlance) towards business models different from or even in opposition to their original goals" (Swartz 2016, p. 88).

The point Swartz raises should not be understated; being from the radical camp does not ineludibly imply being radically more egalitarian or just. Calls for 'transition' and 'transformation' through blockchain resonate with both camps, where projects often advertise themselves as addressing problems in areas including energy (Sivaram 2018), land-registry (Kshetri 2017), identity (Jacobovitz 2016), and governance services (Drucker 2017). Though often there is an apt articulation of the complex internal governance of a project, we will see that the conceptualizations of the political aims and power dynamics within a broader geopolitical context are severely lacking (Markey-Towler 2018). As Hölscher et al. (2018) explain, both concepts, transition and transformation, "refer to change in complex adaptive systems [but are] often employed to different system foci. This has implications on what elements of change are analyzed" (Hölscher et al. 2018, p. 2).

Conceptually, the term 'transition' is predominantly employed to analyze changes in society subsystems like energy and mobility, focusing on "social, technological and institutional interactions" (Loorbach et al. 2017). In contrast, 'transformation' is more commonly used to reflect on "large-scale changes in whole societies, which can be global national or local" (Hölscher et al. 2018, p. 2). In this regard, radical blockchain projects could simply be transitional, where no large-scale societal change is construed, but rather a subsystem with different political premises is imagined and hoped to replace its mainstream counterpart. Similarly, an incorporative project could be thought of as more transformational, because it changes a broader societal process. Both concepts help us to delineate the various system foci, which in turn will enable us to understand the political imaginations behind them.

While many blockchain projects may look transformative or transitional at first, they could also be "creatively destructive', to use Harvey's (1990) vocabulary. To understand this phrase, it is necessary to highlight his concept of "time-space compression" (Harvey 1990, p. 240). In sum, time-space compression refers to the way which the acceleration of economic activities and global interconnectedness leads to the destruction of spatial barriers and distances. For Harvey, "creative destruction is embedded within the circulation of capital itself" (Harvey 1990, pp. 105-6), and thus, refers to industries and jobs that are made redundant as a result of increasing global connectedness. As an illustration, we can look at how the Internet made hundreds of activities associated with publishing, retail, music, and travel completely redundant (Karr 2015). Both radical and incorporative blockchain projects could be thought of as a new vehicle expediting time-space compression, where 'anything of value' or any form of capital can be transferred globally 
much faster, more efficiently, and in a more decentralized manner than previously imagined. Hence, theoretically speaking, both incorporative and radical projects could be simply updating the infrastructure of global trade, finance, business, and government. In that, rather than resolving the inherent contradictions and inequalities of our politico-economic system, as they are often poised to, could both types of blockchain projects rather just be "moving them around geographically"? (Harvey 2010).

Regardless of how transformative blockchain projects may be, most of them articulate, if not embody, some form of prefigurative politics- - "a normative vision of an imagined future reality rather than a description of an actual reality" (Scott 2015). That is, they prefiguratively embody the politics and power structures which they are aiming for. Scott's (2015) concept of the "Techno-Leviathan" adequately expresses a starting point to understanding this approach: "technological infrastructures do not offer an escape from government, they just offer another, competing, governance system with its own power dynamics". We can choose to view rule by code or algorithms as positive or negative, but we must perceive the power in-built into the usage of a system (Scott 2015). With regards to governance within and through blockchain, projects often feature the technology's "design principles" (Tapscott and Tapscott 2016) such as access, disintermediation, decentralization, empowerment, and equality. Our interest here is in how these principles embody socio-political structures differently in different projects, depending on their underlying political imaginaries. For instance, 'if a financial system is no longer governed and regulated by the state (i.e. it is disintermediated), how does the replacement governance system distribute power and create value?' (Table 2).

Through the analysis of patterns through active participation in the blockchain space, journal reflections at events and literature review (which is expounded upon in the next section), we construct a basic typology of blockchain projects (Table 1) into four clusters based on their imaginaries: (i) crypto-libertarians, (ii) crypto-commonists, ${ }^{5}$ (iii) cryptogovernmentalists, and (iv) crypto-collaborativists.

We can distinguish the first two from the latter two quite easily because of one simple reason: the first two are parallel projects attempting to create very different worlds, i.e., blockchain as government. Even then, each one of the clusters conceptualizes their imaginaries differently and, hence, enables a different types of socio-political processes and transformations. The first two both fall under the larger umbrella of crypto-anarchists (Peyrouzet García-Siñeriz 2018, p. 7), while the latter two fall under the banner of crypto-institutionalists. While both the cryptoanarchists aim for detachment from the state, the former,

\footnotetext{
$\overline{5}$ Neologism first proposed by Peyrouzet García-Siñeriz (2018).
}

crypto-libertarians, is unique for its individualistic market-oriented approach to both economic organization and mode of governance (Golumbia 2016). The latter, cryptocommonists, takes the collectivist approach as advocated by commons activists, and, hence, a collaborative approach to governance (Bauwens 2018; Adams 2019). Amongst the crypto-institutionalists, crypto-governmentalists are usually governmental agencies (national or city) who aim to improve government's efficiency, transparency, accountability, and security using blockchain (Hancock and Vaizey 2015; Ølnes et al. 2017). Such projects take the approach of using blockchain in government. Crypto-collaborativists are those public-private partnerships or coalitions that aim to collaboratively experiment with blockchain experiment with the existing political infrastructure as well as create new ones. This is the group that either designs projects for government or in collaboration with government. While these clusters are not fixed, they begin to shed light on the prefigurative element of the political imaginaries of these projects.

To highlight the importance of identifying and analyzing these imaginaries, we assert that "technological opportunities do not enter into economic and social life without deliberate efforts and choices" (Archibugi 2017, p. 541). We oppose our frame to Marxian and Deweyan technodeterminism (Smith and Marx 1994), which considers social relations, organizational structures, and cultural practices predominantly a product of a society's techno-economic infrastructure. Since possible socio-political scenarios will perpetuate the mainstream only with deliberate use, identification of the imaginaries becomes even more important, because our efforts and choices of designing and using particular systems will enable particular socio-political realities.

After outlining our methodology, we critically analyze the most cited and popularly misconceived design principles of blockchain projects, and follow with a discussion and research agenda. ${ }^{6}$

\section{Methods: digital ethnography and immersion in social worlds}

This article is principally an outcome of the first author being immersed in the blockchain space for the past 3 years in Europe-primarily in the Netherlands and the UK. The methodological approach was predominantly inspired by the iterative principles of digital ethnography (Pink et al. 2016;

\footnotetext{
${ }^{6}$ In this article, we make a distinction between blockchain platforms like Ethereum or EOS and projects like Status or Augur. However, we also acknowledge that this is not a strict distinction, since 'projects' like Colu or Bancor, allow currencies and projects to emerge from within them. Platforms, projects, and hybrids, indeed have political imaginaries at play, but we confine ourselves to discussing projects in this article for conceptual clarity.
} 
Hjorth 2017; Hsu 2017) and supplemented with participatory action and qualitative methods used in social sciences (Bergold and Thomas 2012). Digital ethnography begins with the idea that the "digital has become a part of the material, sensory and social worlds that we inhabit" (Pink et al. 2016 , p. 7) and, hence, must be an integral feature in most forms of ethnographic research. Furthermore, this approach helps takes notice of how the digital is increasing, reducing, and transforming our socio-political life and agency in our social worlds. The social world ${ }^{7}$ that blockchain innovation takes place is neither solely online or offline, and, hence, needs to be treated as such during empirical research. Since each social-political world comes with its own variety of communication norms, rules, networks, behaviors, activity infrastructures, and operational structures, an ethnographer has to learn the language and energy of the world to begin understanding it. As Pink et al. confirm, "immersion, participant observation and 'the everyday' are three ideas bound up with how we study social worlds" (Pink et al. 2016, p. 436). This form of ethnography is a reflexive methodology that allows researchers to develop individualized approaches for each environment and is the most appropriate tool for understanding online environments (Ward 1999).

To do research within the social worlds of blockchain projects, activities included participant observation to analyze the issues raised and debates carried out at monthly blockchain MeetUps for a year in Amsterdam (12); online and offline hackathons annually (2 hackathons); weekly presence in Slack teams and other team collaboration platforms ${ }^{8}$ (6 teams); and other online forums like Reddit (4 forums regularly); attendance at blockchain conferences (4 European conferences), online seminars (3 seminars) and after-parties; and conference calls with project leads and entrepreneurs; analysis of data from, wikis and blogs produced by respondents, as well as online focus groups. The offline involvement at events allowed many opportunities for discussions and informal interviews with ICO heads, expert practitioners, blockchain figureheads, government officials, coders, researchers, experts, and activists (25). However, considering the briefness and casual setting unsuitable for audio recording, most conversations were recounted as

\footnotetext{
${ }^{7}$ Understood as "a form of social organization which cannot be accurately delineated by spatial, territorial, formal or membership boundaries" (Unruh 1980, p. 271). Applied to the hybrid space of online and offline interactions socio-political worlds are construed as "relatively unbounded...domains of social life", where ethnographers immerse themselves with research participants for long periods of time (Pink et al. 2016, p. 434).

8 Team collaboration platforms or team communication platforms (TCPs) have are an "are an emergent class of social collaboration technology that combine features of multiple enterprise social media including social networking platforms and instant messaging" (Anders 2016, p. 224).
}

non-verbatim journal reflections. The online data collection comprised of a daily and weekly routine of: reading already joined threads and channels, contributing to debates, virtually archiving notes, taking field notes, and placing them in hand-made cross-reference diagrams. Furthermore, the choice of which blockchain projects to analyze was driven by the research process itself, where projects were recommended or discussed during the immersion activities. However, it should be noted that projects were deliberately chosen across the political spectrum after the basic typologies were observed-from crypto-anarchists to crypto-institutionalists (which had very different social worlds ${ }^{9}$ ) - in search for outliers and differentiating data.

The evidence and insight acquired through the above method of immersion is used in concert with several other sources of secondary data, including academic studies, White Papers, ${ }^{10}$ cryptocurrency and technology blogs, news websites, and popular media. Considering the nature of the study - to identify and analyze the political premises of blockchain projects- these sources have been used as primary data, since they are often the only articulation of the political imaginaries. We used these documents to tease out the political imaginations in the author bias, ethics disclaimers, and vision statements, and place them in cross-reference diagrams. Many of the non-academic sources which were consulted remain in the basement of the internet, which is not only hard to find, but dominated by groups which prefer to remain detached from popular media. Conversely, in our scholarly literature review, we noted that many articles concerning blockchain cite the popular news websites like CoinDesk and CoinTelegraph, as well as blogs and forums like Hacker Noon and subreddits like r/Blockchain/. Indeed, as the Misfit Economy points out, activities in the grey area between 'deviance' and the 'normal' are often the cradles of innovation (Clay and Phillips 2015). Furthermore, they offer us a way to 'reinvent the wheel'-create new alternative systems that at least initially operate outside the dominant institutional setting. Homero Gil de Zúñiga et al. (2010) reiterate these points that we need to take into account "a new type of political advocate" (p. 36) who are "increasingly relevant to political discourse...[who] evidence of the emergence of a hybrid participation that combines the

\footnotetext{
${ }^{9}$ Crypto-anarchists projects were usually global, translocal, or local projects, which involved a lot of online collaboration. Contrastingly, crypto-institutionalists were almost always national, regional or local projects which required many traditional techniques such as interviews and workshops.

10 "A white paper is a document which includes an outline of a problem that the project is looking to solve, the solution to that problem as well as a detailed description of their product, its architecture and its interaction with users". For more info, refer to: (CoinTelegraph 2018). Examples of the white papers of projects include all projects listed in Table 1.
} 
virtual and real world realms of political engagement and action" (Gil de Zúñiga et al. 2010, p. 45).

Both online and offline sources of information were crossvalidated though an iterative form of pattern analysis. This analysis comprised of identifying patterns that emerged in how the themes (highlighted in the next section) were conceptualized in different blockchain projects. Hence, the pattern markers were found in the various data sources outlined above and subsequently clustered, as shown in Table 1 . As noted, there was no fixed criteria with which to cluster the projects. Instead, it evolved over the course of the research. These criteria are reflected in the first column of Table 1. It is this evolution through the analysis of patterns and crossvalidation with experts and academic analyses that led to the outlining the questions and prefigurative political expressions of blockchain projects in Table 2 .

\section{Results: rethinking blockchain's design principles-equitable design $\neq$ equitable politics}

Blockchain is often cited as a panacea for many sectors of the digitally enabled economy (Kshetri 2017), and as infrastructure for a variety of public services (Killmeyer et al. 2017), including land registry (Oprunenco and Akmeemana 2018), healthcare, recycling (Saberi et al. 2018b), and many more (Vigna and Casey 2016). However, the political motivations behind these projects are seldom questioned. ${ }^{11}$ Cryptocurrencies, one particular set of use cases of blockchains, have been closely associated with a libertarian ideology, but these are underdeveloped conceptualizations at best (Faife 2016). For instance, libertarians could be statists, advocating a limited government; or anarcho-capitalists and cyberlibertarians, who would like to hand over all power to the markets. In CoinDesk's Q2 2018 survey of 1200 cryptocommunity respondents, they concluded that $52 \%$ was distinctively right-wing, while $45 \%$ was leaning towards the left (CoinDesk 2018, pp. 105-106). While these statistics are enlightening for a superficial understanding of the cryptocurrency field, they reflect the political inclinations of those who are active users of cryptocurrencies, rather than those individuals creating blockchain-based projects. In contrast, our aim is to understand the political premises that inform the design of the projects themselves, rather than their users. More specifically, through asking a series of questions, we seek to be able identify the clusters of projects and better predict the associated socio-political implications.

\footnotetext{
11 There are some more developments particularly in the field of cryptocurrencies such as: (Golumbia 2016).
}

In the following section, we use published scholarly research and insight from non-academic sources in concert with reflections, cross-validating interviews with experts and patterns identified during the ethnography. The analysis will be used to formulate fundamental questions about the political imaginaries and their prefigurative political expressions. The themes listed below were the most popular, yet, often repetitively misconceived features of blockchain projects identified during the course of the first author's empirical research. The questions formulated are considered fundamental owing to: the fact that each project researched has cited the misconceived terms; they determine the basic functioning and design of the project; expert interviewees considered them as fundamental in defining the expressions of political imaginaries of blockchain projects. The themes lay the groundwork, in terms of conceptualization, to ask specific questions regarding the four clusters of expressions outlined in Table 2: political imaginaries, nature of transformative potential, prefigurative political design, and incentives and values.

\section{Decentralization and disintermediation}

Perhaps, the most glorified characteristics of blockchain are its capacity to decentralize and disintermediate. These closely related concepts and often conflated features are appealed to by all initiatives. With blockchain, every node in a network retains a copy of all transactions that are carried out on a system, effectively eliminating the need for a thirdparty intermediary like payment processors, banks, and even governments. The decentralization of the nodes allows for disintermediation, but does not necessitate it. For instance, disintermediating from centralized institutions could be carried out through a peer-to-peer $(\mathrm{P} 2 \mathrm{P})$ protocol which allows two parties to transact without an intermediary. A cryptocurrency — such as Bitcoin — would be one such example: an electronic cash system which allows peers to transact tokens without any middleman writing the terms of transaction. Bitcoin can decentralize transaction data, make it transparent in a public ledger, and replace the traditional financial intermediaries. Each transaction is instead validated by miners (a group of volunteers) who compete to solve a mathematical puzzle to gain a small reward. However, it has, nonetheless, created an alternative governance system which has recentralizing tendencies in the form of "colossal mining operations...with risks of collusion or cartelization" (Atzori 2015, p. 16). As Dodd explains, Bitcoin's "social life" is characterized by asymmetries of wealth and power that are not dissimilar from the mainstream financial system" (Dodd 2018, p. 35). This raised several questions for our empirical research, such as: once we remove traditional central authorities, who does our blockchain-based system give power to? Which actors are most likely to become more powerful as a consequence of decentralizing a particular system? Are 
there, or could we create cryptocurrencies with non-libertarian imaginaries? Such questions as well as the problematic understanding of decentralization influence the various expressions of blockchain projects identified in Table 2. For instance, if traditional authorities are replaced, who then sets the affordances and constraints for the user?

While the power relations and politics of Bitcoin have been addressed elsewhere (Golumbia 2015), we can ask similar questions about all blockchain projects. Blockchain projects in different sectors have different sets of actors, each of whom have different aims and scope. For instance, take the case of e-Estonia, a series of projects launched by the national government of Estonia to digitize the interactions of citizens with the state. Through our empirical work, we asked what does creating a "virtual, borderless, blockchained, and secure" (Heller 2018) government entail in terms of a cyber-governmentalist imaginary? Does the transparency and efficiency brought about by virtualizing governance services change arrangements of power and decision-making, or simply increase accountability and reduce chances of coercion? Does the decentralization of data ownership entail any disintermediation from the government itself, or rather deepen institutional control? If we are able to conceptualize cases like this, we will be in a better position to understand the nature of the project. This includes, for example, whether it is incorporative or radical, the potential for time-space compression and/or creative destruction, the aims, scope, and features of transformation or transition. The aim of this article is provide a frame to systematically and thoroughly investigate such issues as is delineated in Table 2.

With regards to disintermediation in general, arguably one of the most important questions that emerged during the course of our research is which types of intermediaries might we want to get rid of, and why? While there are many projects that decentralize for the sake of decentralization, Schneider (2017) notes that there needs to be more nuance in understanding whether or not decentralizing everything is either feasible or makes systems more accountable. His point is that since many decentralized systems eventually show different forms of centralization, projects must be very specific about "the particular features of a system a given design seeks to decentralize". Furthermore, he explains how recentralization often occurs because of "imbalances of power that operate outside the given network". For instance, wealth in the cryptocurrency world is usually correlated to wealth in the external economy, as well as early adoption and education (Schneider 2017). To counteract these concentrations of power, projects can use a diversity of modes of decentralization, or checks and balances-each informed by their own political imagination. Mechanisms and software that decentralize complex systems can bring liberating possibilities; yet they also risk creating radically unaccountable and coercive concentrations of power (Atzori 2015; Reijers and Coeckelbergh 2016). In that, Table 2 makes an effort to expose the various modes and expressions of decentralization and disintermediation implicit in blockchain projects.

As an illustration of the above point, take the case of the socalled sharing economy initiatives such as Airbnb and Uber, which rely on the "contributions of users as a means to generate value within their own platforms" (De Filippi 2018, p. 2). These companies have been called tightly controlled, profit-driven corporate platforms which exploit their users, leading to global protests (Largave 2017; Lownsbroug 2017). As a response, some crypto-commonist initiatives are built as "platform cooperatives", which are "collectively owned and governed by the people who depend on and participate [in them]" (Sutton et al. 2016) deriving from a long history of cooperative economics. For instance, in the FairCoin Coop, all decision and strategies are made in monthly assemblies (König and Duran 2016). As such, the power relations are of a collaborative nature, with the politico-economic imagination behind these initiatives being commons-based rather than market-based. Of course, equality in design of a platform does not necessarily imply the same qualities will exist practice. A commons-based system cannot just be a simple bolt-on set of principles to an existing project or business. It has to be conceived as a political choice and involves an entirely different starting point than a regular start-up. Hence, it becomes very important to consider political premises underlying the variations of decentralization, both at the design level (political imaginaries and prefigurative political design in Table 2) and at the implementation level (nature of transformative potential and incentives and values in Table 2). The more precisely we can delineate features of the technical system, the more aptly we can determine the types of socioeconomic and political interactions the system can enable.

\section{Access, inclusion, and empowerment}

Blockchain, it is claimed, has the capacity to "bank the unbanked" (Thellmann 2018), create a "financially inclusive future" (Fork 2018), "break the poverty chain in the global south" (Kshetri 2017, p. 1710), and "empower the poor" (Thomason et al. 2018, p. 138). These are some of the commonly made claims about blockchain. Searching similar phrases leads to a series of academic studies, opinion pieces, and actual blockchain projects which commonly cite these phrases. While the intent of these projects is seemingly to create a more inclusive financial, economic, and political system, their diverse actualizations come with some deeply problematic politics and imaginaries. First, there is the issue of access. For the moment, only $55 \%$ of the world has access to the Internet, and this is unevenly distributed geographically (Graham 2014; Poushter 2016; World Population Stats 2018). Since most blockchain projects require access to at least a smartphone and the Internet, it seems unlikely the technology will be a panacea for poverty in the entire region of the global south 
(Kshetri 2017). Furthermore, there is an entirely different set of power and information asymmetries and cultures in the developing world which all need to be reckoned with in the design of alternative systems (Castor 2018; Kshetri and Voas 2018).

The social aspects of both the digital divide and democratic divide become increasingly relevant when different aspects of socio-political life are put online. As Min (2010) explains, the digital divide could cause "additional disadvantages for the already marginalized groups in society" (Min 2010, p. 22). The democratic divide, which concerns people's different usage of the internet for political purposes, can be expanded to the blockchain space, by imagining people's differential attitudes and skills to understand what the system allows and disallows them from doing (Norris 2001). As Lubin et al. (2018) assert, expecting these diverse populations to embrace new technological systems created by start-ups in the blockchain world that restructure daily life transactions "wholesale oversimplifies the social process of technological system" (Lubin et al. 2018, p. 13).

During our empirical research, we found a host of innovative solutions, like cheaper remittance systems (Lashkov 2018), that will make headway in solving particular issues in particular places. For instance, project Bifröst works with a consortium of non-profit companies to help develop "cash transfer programs" which will use blockchain and cryptocurrencies to enable a new world of micro-finance and cheaper remittances (Bifröst 2018). However, it is hard to miss that the overall crypto-anarchist approach darkly resembles a variation on "authoritarian paternalism", wherein the blockchain innovation community-mostly situated in North America and Europe - decides the best solution for the disenfranchised populations continents away (Scott 2015). As Scott puts it, "there is something obnoxious about the way that university-educated tech optimists constantly invoke the mythical land of "Africa", with the imagined African person in the imagined African village, using Bitcoin to escape corruption in their country" (Scott 2015). Take for instance Zipcoin, which is digitalizing the African market through a payment and remittance system (Zipcoin 2018; Cocking 2019). Such vision statements in global development rhetoric and the blockchain start-up community carry with them a political ambition of imposing techcentric solutions for an often non-tech adept community. Their political premises may be radical or incorporative in theory, but our interviews and experts explained how applying libertarian or commonist ideals in the technical design to systems where the cultural and political context is not libertarian nor commonist is deeply problematic. Furthermore, it may actually worsen socio-economic inequalities in many situations.

As Lubin et al. explain, with regards to financial inclusion, many projects also assume "that under-resourced localities define "value" in the same way as westernized communities do-via fiat currency-rather than by other quality of life measures" (Lubin et al. 2018, p. 13). The latter includes, for example, access to food and basic resources, community solidarity, social capital, or direct exchange of services. Hence, the "value as incentive" (Radziwill 2018, p. 35) that is commonly cited in the white papers of cryptoanarchist blockchain projects may not hold, owing to differing political ambitions-both in under-resourced and developed contexts. In general, an incentive in any design element of a system influences the behaviors of anyone participating in the system (Barrera 2018). More simply, they encourage communities of participants to collaboratively create value, which, in turn, will ensure the success of their platform. According to this scheme, working for your self-interests will benefit the whole (antifragile 2017).

Most blockchain-based systems use tokenized pay-forperformance incentive schemes in which participants are rewarded according to the performance of the token's value. However, as Barrera (2018) aptly points out, there are many problems that could arise from poorly choose performance metrics. For example, innocuous or malicious gaming ${ }^{12}$ could exacerbate the inequalities in communities where there is already inequality in terms of capital investment, education, expertise, and power. Furthermore, if the politicoeconomic aim is the empowerment of disadvantaged people, we must then question whether such systems are referring to individual empowerment or collective empowerment-and whether one necessarily translates into the other. It is expressions of such embodied values that the "incentives and values" column in Table 2 attempts to expose. BitPesa, which is the first African digital money transfer company, succeeded in removing correspondent banks from the transaction chain. However, by disintermediating cash transfers, does it necessarily mean that it will be used for collective empowerment or reiterate local inequalities? (Yen 2017; Flore 2018). For instance, those who climb the steep learning curve of exploiting the emerging systems on the blockchain may benefit far more quickly than others, creating a series of issues regarding accountability and the modes of decentralization most suited for the job.

Also, worth reflecting upon here, are the many innovative blockchain projects whose political imaginations regarding inclusion, access and empowerment are not yet realized; rather, they are currently in the process of being developed. For instance, RightMesh "is on a mission to connect the next billion users without infrastructure" [instead of laying new fiber optic cables for Internet connectivity, it can transform smartphones into nodes that form a network, and connectivity

\footnotetext{
${ }^{12}$ Barrera outlines three other problems: free-riding, multi-tasking and risk misalignment. "Innocuous Gaming: Users may take actions that increase token value but do not have a positive impact on the value of the platform".

"Malicious Gaming: Users may take actions that increase token value to the detriment of platform value." (Barrera 2018).
} 
between them is achieved through Bluetooth and Wi-Fi (which is inherent to the device)] (RightMesh 2018). While there are many initiatives "banking the unbanked", this one "retrofits existing mobile applications and builds new, P2P mesh applications" (RightMesh 2018). When implementing solutions beyond simple connectivity, RightMesh will have to be careful not to replicate, reiterate, or create new forms of inequalities through power imbalances in a system. Nonetheless, creating such mesh networks for context-specific solutions and working with local actors could create new forms of techno-political innovation. Another such example is Colu, a "decentralized payment system for local communities" (Colu Technologies DLT limited 2018, p. 2) upon which communities can create their own currencies and implement mechanisms of consensus and power depending on their place-based definitions of value and culture. Such umbrella systems using blockchain enable a new way of working, where place-based actors can access an open-source software and adapt it to their context-sensitive needs using a global pool of volunteers for support.

\section{Code is law and modes of coercion}

"Code is law", another way of referring to "governance by technologies", is the idea that software coding can be understood as a form of law. Campbell-Verduyn (2017) explains that certain design features of technologies themselves can "reframe, redefine, and reconstitute the mundane activities of the social actors and social process under-pinning global governance" (Campbell-Verduyn 2017, p. 8). Specific architectures of general-purpose technologies, as described earlier, can be understood as "arrangements of power" (DeNardis 2012, p. 721) which weigh heavily on the conditions of possibility for socio-economic interactions. As Benkler states, the Internet has been coded to allow certain "affordances and constraints" (Benkler 2011, p. 722) around values which we may not be able to identify at first. Building on this idea, Filippi and Hassan (2018) assert that "code has progressively established itself as the predominant way to regulate the behavior of Internet users". Accordingly, with the advent of blockchain and associated smart contracts, code is assuming such a strong role, that it is possible to identify a shift from 'code is law' (code has the effect of law) to 'law is code' (law is actively being defined as code) (De Filippi and Hassan 2016).

Contextualizing this shift in terms of political imagination, there is a stark difference in the way which socio-economic interactions will be regulated. The current legal system is enforced "ex-post" (after the event) through state intervention, while in technological systems, it is in-built in the system, and, hence, is enforced "ex ante" (before the event) through code (De Filippi and Hassan 2016). This implies that the designers, owners, and controllers of the system can choose to structurally enable and disable certain types of socio-economic interactions, political action, and processes on their technical systems. Through empirically scanning blockchain projects, decentralization evangelists, and technoutopians from both the radical and incorporative camps, we identified their shared claim of the possibility to reduce the role of coercive institutions, such as the state and other regulatory bodies, by pre-defining what is and is not allowed (Atzori 2015). Correspondingly, the burgeoning reliance on technology in this regard, signals the urgency of questioning and analyzing the in-built ethical-legal and political features of projects. If we understand that blockchain projects are reducing certain traditionally coercive institutions, we must ask which new forms of coercion emerge within blockchain governance systems - both internally and externally. According to Myers, "reproducing the coercive role of the state in a decentralized yet less constrained manner does not create a more just society" (Myers 2017, p. 246); rather, the same political ideals of libertarian democracy will be implemented in a new and debatably more coercive form.

We are already witnessing government-led pilots experimenting with political rule by algorithm (Calzada 2018). China's social credit system is a national reputation system which aims to standardize the assessment of citizens' and businesses' reputations and grant rewards. Popularly referenced to TV show Black Mirror (Jeferson 2018), it is being described in the media as a politically dystopic shift and another form of surveillance capitalism (Cinnamon 2017; Chorzempa et al. 2018). Similarly, through our research, we ascertained that many blockchain projects prefiguratively implement politicized ideas of incentives to instill certain types of behavior. For instance, the aforementioned example of Colu (Joey 2018) and community cryptocurrencies encourage and incentivizes people to take part in the local economy (Birch 2015; Tarasiewicz and Newman 2015). The imaginaries of such a system share some similarities with the crypto-commonists, circular economy, and politics of local consumption (Mougayar 2016; Circle Economy 2018). There are other exploratory ideas of creating a Co-op Coin which would embody principles of the collaborative economy and use organizational models of cooperatives (Sylvester-Bradley 2018). Design features are highly politicized and have profound implications on the types of activity that can be carried out by civil society. With each project, we must question which values are encoded in the system, who controls it, which organizational structure is present to form consensus, and what are the political visions of the code.

\section{Discussion: screening blockchain projects- an exercise in political imagination}

Our central claim in this paper is that blockchain experiments embody the politics, i.e., affordances and constraints (Benkler 2011, p. 722), which they aim to enable in society. 


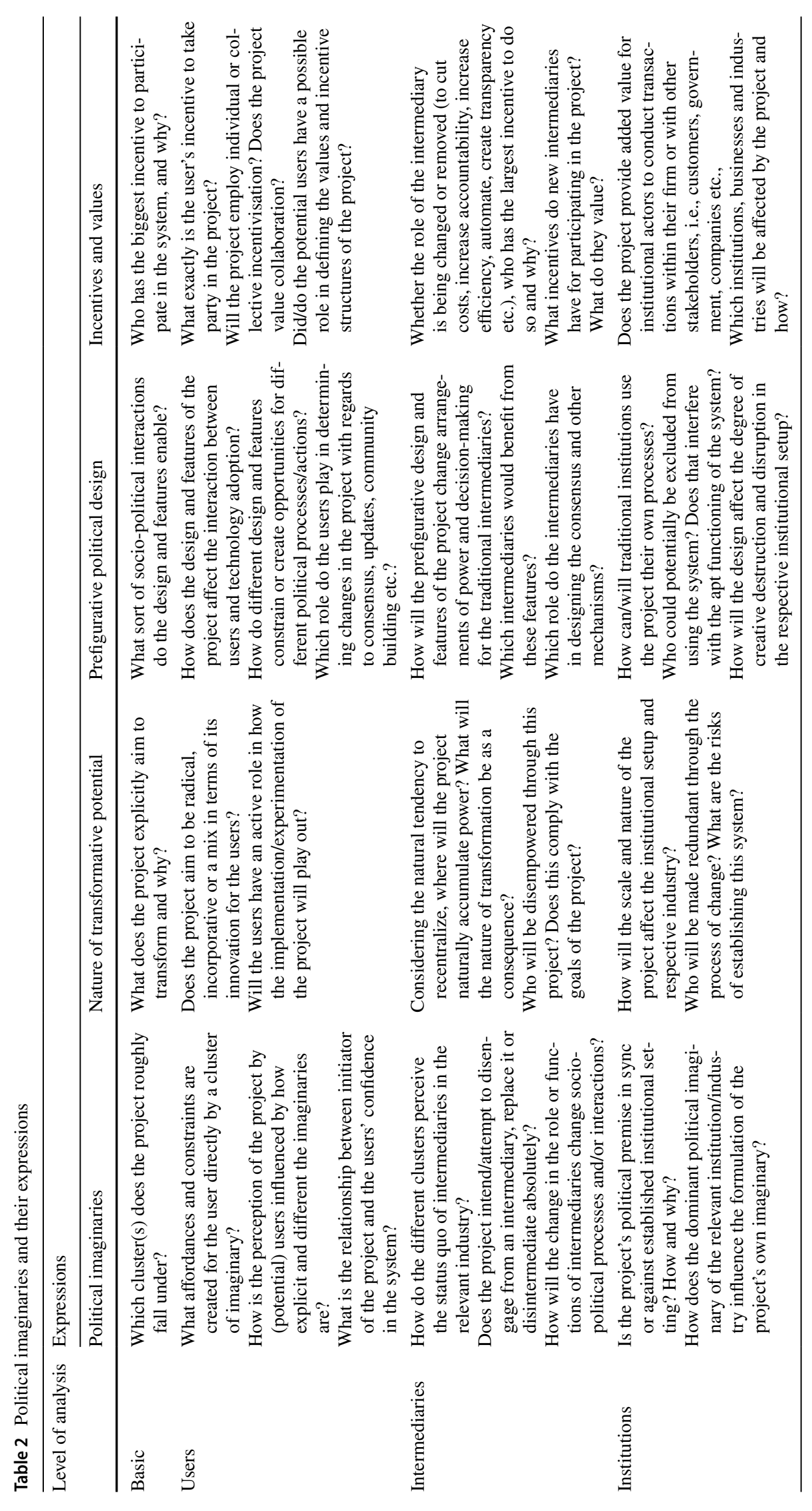


This, in turn, depends on the political imaginaries on which the projects are built. In this section, in the spirit of setting a future transdisciplinary research agenda, we propose a frame to question, cluster, and analyze the imaginaries and their consequences. We do so in response to the current knowledge gap. That is, in the blockchain space, there are many analysts and practitioners who have attempted to compare the types of blockchains (Grakov and Chiara 2018), design features of blockchain platforms (not projects) (edChain 2018), cryptocurrencies (Desjardins 2018), and even create decision-trees of when to use a blockchain (World Economic Forum 2018; Zitter 2018). Though such tables elucidate the many differences between the technical features, they are far from a graspable comparison of the political premises behind them. Furthermore, it can also be noted that majority of the academic analysis and consultancy reports that were reviewed for this article regurgitate the imaginaries of blockchain projects without any critical reflection. Contrastingly, our aim in Table 2 is to create a broader frame which functions less as a table of comparisons, and more as an iterative framework which opens up new avenues of research and experimentation which can be collaboratively worked on by academics, practitioners, technologists, and politicians. It can also be used as a tool by practitioners to understand the political implications of their design, while also elucidating how implementation may pose certain difficulties.

Relevant here is the work of Risius and Spohrer, who delineated a "blockchain research framework" which is "conceptualized as an intersection of activities that blockchain developers and users can undertake and the levels of analysis on which these activities wield influence" (p. 389). They have adapted an established framework from the social media research agenda of Aral et al. to identify topics and find connections that have not been considered by other blockchain research. Deriving inspiration from their work, we have recreated the table below which identifies topics and finds connections specifically with regards to expressions of political imaginaries, transformative potential, prefigurative political designs, and incentives.

We use the vocabulary and analysis from the previous sections in concert with our wider empirical journal reflections to construct the questions within the frame. In Table 2, the left-most column separates the levels of analysis: users, intermediaries, and institutions. At each of these levels, a series of (research) questions are articulated with respect to each "expression". The row titled "basic" describes the question of the expression itself. For instance, a project's "nature of transformative potential" analyzed at the level of the user will ask how and what exactly will change for the user. In other words, will it simply be an incorporative project, where the user's role, power, and influence will remain the same, or will they change in the proposed system?
This frame can be used reflexively for different purposes. For example: (i) a project can be analyzed from the perspective of just the user, intermediary, or institution, with regards to each one of the expressions in the columns. (ii) A project can be analyzed from all levels of analysis with regards to only one expression. (iii) The relationship between two or more expressions can be analyzed through a study or pilot. Though the frame is open to interpretation and use, we must clarify that the questions were written with the intention of being project-specific.

\section{Concluding remarks: the political agency of research on innovation}

This article has attempted to articulate a critical frame through which to analyze the socio-political under-pinnings of blockchain projects. Yet, our intention in this article is not to promote either blockchain utopianism or cynicism; nor is it to advocate for a crypto-anarchist or crypto-institutionalist approach. Rather, it is to articulate a call and research frame to delve deeper into how the political imaginaries behind both the technical design and implementation of projects prefiguratively create the infrastructure of politics. Furthermore, in contrast to many of the articles that were reviewed during this research, we do not make claims that blockchain is suited for socialist or libertarian systems. Rather, we simply encourage practitioners to critically and reflexively analyze the often underdeveloped political underpinnings of their projects. Indeed, it is relevant to mention how little scholars trained in political and social sciences have addressed the imaginaries and corresponding implications mentioned in this paper. Technology is not neutral. However, it is only with considerable, deliberate efforts, and both individual and collective choices that technology restructures and reorients our socio-economic lives.

Concerning various design features that most contemporary projects cite, we advocate a more thorough form of prototyping that could elucidate how they will play out. For instance, instead of decentralizing for the sake of decentralizing, we suggest that it is more appropriate to first ask which aspects of particular systems would function better in a decentralized way? And for who? Would they enable a new form of political reality? Why would that be desirable? When reconfigured in this way, the "measure of a technology should be its capacity to engender more accountable forms of trust" (Schneider 2017).

To conclude, by envisaging new forms of organization, politics, business, and trade associated with emerging technology, we will also, to an extent, be able to guide them. In other words, we become better equipped to paint a picture of the future which we desire, considering blockchains' capacity to alter the socio-technical landscape through expediting 
time-space compression. In the words of Vinay Gupta, we must "make a clear image of the future we want, otherwise we are going to get the kind of future that happens by accident" (Gupta 2018).

Acknowledgements We are very grateful to all the interviewees and participants who took part in the research.

Funding This project has received funding from the European Union's Horizon 2020 research and innovation program under the Marie Skłodowska-Curie Grant Agreement No. 674962.

\section{Compliance with ethical standards}

Conflict of interest The authors declare no conflict of interest.

Ethics statement SUSPLACE has formulated an ethical policy for the program. The research project proposal underlying this research has been approved by the hosting university and the ethical committee of SUSPLACE.

Open Access This article is licensed under a Creative Commons Attribution 4.0 International License, which permits use, sharing, adaptation, distribution and reproduction in any medium or format, as long as you give appropriate credit to the original author(s) and the source, provide a link to the Creative Commons licence, and indicate if changes were made. The images or other third party material in this article are included in the article's Creative Commons licence, unless indicated otherwise in a credit line to the material. If material is not included in the article's Creative Commons licence and your intended use is not permitted by statutory regulation or exceeds the permitted use, you will need to obtain permission directly from the copyright holder. To view a copy of this licence, visit http://creativecommons.org/licenses/by/4.0/.

\section{References}

Adams D (2019) How Blockchain Economies align incentives around the Commons. In: Giveth-Mediu. https://medium.com/givet $\mathrm{h} /$ blockchain-economies-and-the-commons-cdb67dd1a163. Accessed 30 July 2019

Anders A (2016) Team communication platforms and emergent social collaboration practices. Int J Bus Commun 53:224-261. https:// doi.org/10.1177/2329488415627273

antifragile (2017) The 7 design principles of a Blockchain Economy. In: Steemit. https://steemit.com/steemit/@ antifragile/the-7-desig n-principles-of-a-blockchain-economy. Accessed 18 Jan 2019

Archibugi D (2017) Blade Runner economics: will innovation lead the economic recovery? Res Policy 46:535-543. https://doi. org/10.1016/J.RESPOL.2016.01.021

Aslam N (2018) Economist Nouriel Roubini Says "Blockchain Is Useless, All ICOs Are Scams”. In: Forbes. https://www.forbes.com/ sites/naeemaslam/2018/08/31/nouriel-roubini-says-blockchain -is-useless-all-icos-are-scam/\#78c638c83f3a. Accessed 19 Oct 2018

Atzori M (2015) Blockchain technology and decentralized governance: is the state still necessary? J Gov Regul. https://doi. org/10.22495/jgr_v6_i1_p5

Atzori M (2018) Blockchain governance and the role of trust service providers: the TrustedChain ${ }^{\circledR}$ network. J Br Blockchain Assoc 1:1-17. https://doi.org/10.31585/jbba-1-1-(3)2018
Baker M (2016) The prefigurative politics of translation in placebased movements of protest: Subtitling in the Egyptian Revolution. Translator 22:1-21. https://doi.org/10.1080/13556 509.2016.1148438

Banco Bilbao Vizcaya Argentaria (2019) What is the difference between DLT and blockchain? In: Communications. https:// www.bbva.com/en/difference-dlt-blockchain/. Accessed 19 Oct 2018

Barrera C (2018) Blockchain incentive structures: what they are and why they matter. In: Prysm Gr. Mediu. https://medium.com/ prysmeconomics/blockchain-incentives-101-what-they-areand-why-they-matter-5127afb56aeb. Accessed 18 Jan 2019

Bauwens M (2018) Commons and Blockchain. In: P2P Found. https ://blog.p2pfoundation.net/michel-bauwens-commons-andblockchain/2018/12/18. Accessed 30 July 2019

Benkler Y (2011) Networks of power, degrees of freedom. Int J Commun 5:721-755

Bergold J, Thomas S (2012) Participatory research methods: a methodological approach in motion. Forum Qual Soc Res 13:191-222

Beveridge R, Koch P (2017) The post-political trap? Reflections on politics, agency and the city The post-political trap? Crit Comment Urban Stud 54:31-43. https://doi.org/10.1177/0042098016 671477

Bifröst (2018) Bifröst protocol: cross-chain bridges. https://github.com/ thorchain/Resources/blob/master/Whitepapers/Bifrost-Protocol/ whitepaper-en.md. Accessed 15 Jan 2020

Birch DGW (2015) What does cryptocurrency mean for the new economy? In: Handbook of digital currency. Elsevier, pp 505-517

Böhme R, Christin N, Edelman B, Moore T (2015) Bitcoin: economics, technology, and governance. J Econ Perspect 29:213-238. https ://doi.org/10.1257/jep.29.2.213

Bollen R (2016) The legal status of online currencies are bitcoins the future? SSRN Electron J. https://doi.org/10.2139/ssrn.2736021

Brody A (2019) Techno-Utopianism in Blockchain is stupid. In: Mediu.-Purple Rhizome. https://medium.com/purple-rhizo me/techno-utopianism-in-blockchain-is-stupid-c406762e3fbb. Accessed 5 Dec 2019

Browne C, Diehl P (2019) Conceptualising the political imaginary: an introduction to the special issue. Soc Epistemol 33:393-397. https://doi.org/10.1080/02691728.2019.1652859

Calzada I (2018) 'Algorithmic nations': seeing like a city-regional and techno-political conceptual assemblage. Reg Stud Reg Sci 5:267-289. https://doi.org/10.1080/21681376.2018.1507754

Campbell-Verduyn M (2017) Bitcoin and beyond: cryptocurrencies, blockchains, and global governance, 1st edn. Routledge, London

Carpenter SR, Winner L (1978) Autonomous technology: technics-outof-control as a theme in political thought. Technol Cult 19:142. https://doi.org/10.2307/3103332

Casino F, Dasaklis TK, Patsakis C (2019) A systematic literature review of blockchain-based applications: Current status, classification and open issues. Telemat Inform 36:55-81. https://doi. org/10.1016/J.TELE.2018.11.006

Castor A (2018) Blockchain's greatest impact will be in developing countries, says... I Bitcoin Magazine. In: Bitcoin Mag. https:// bitcoinmagazine.com/articles/blockchains-greatest-impact-willbe-developing-countries-says-upenn-lecturer/. Accessed 16 Jan 2019

Catalini C, Gans JS (2016) Some simple economics of the blockchain. SSRN Electron J. https://doi.org/10.2139/ssrn.2874598

Chorzempa M, Triolo P, Sacks S (2018) China's social credit system: a mark of progress or a threat to privacy? Peterson Inst Int Econ 18:1-11

Cinnamon J (2017) Social injustice in surveillance capitalism. Surveill Soc 15:609-625. https://doi.org/10.24908/ss.v15i5.6433 
Circle Economy (2018) Blockchain and the circular economy: an exploration. https://www.circle-economy.com/blockchain -and-the-circular-economy-an-exploration/\#.W9snQHpKhn 4. Accessed 1 Nov 2018

Clay A, Phillips KM (2015) The misfit economy: lessons in creativity from pirates, hackers, gangsters, and other informal entrepreneurs, 1st edn. Simon \& Schuster, New York

Cocking S (2019) Digitalising the African markets with Zipcoin Remit's positive solution 3.0-Irish Tech News. https://irish technews.ie/digitalizing-the-african-markets-by-zipcoin-remit/. Accessed 15 Jan 2020

CoinDesk (2018) State of Blockchain Q2. In: CoinDesk Res. https:// www.coindesk.com/research/state-of-blockchain-q2-2018/?slide $=93$. Accessed 30 Oct 2018

CoinTelegraph (2018) What is a white paper and how to write it. In: Coin Telegr. https://cointelegraph.com/ico-101/what-is-a-white -paper-and-how-to-write-it. Accessed 24 Oct 2018

Colu Technologies DLT limited (2018) Colu Local Network (CLN): whitepaper

Conley JP (2017) Blockchain and the economics of crypto-tokens and initial coin offerings. Vanderbilt University Department of Economics Working Paper 17-00008

Dafoe A (2015) On technological determinism: a typology, scope conditions, and a mechanism. Sci Technol Hum Values 40:10471076. https://doi.org/10.1177/0162243915579283

De Filippi P (2018) Blockchain: a global infrastructure for distributed governance and local manufacturing. In: Diez T (ed) The mass distribution of almost everything. Institute for Advanced Architecture of Catalonia, Spain

De Filippi P, Hassan S (2016) Blockchain technology as a regulatory technology: from code is law to law is code. First Monday. https ://doi.org/10.5210/fm.v21i12.7113

De Filippi P, Loveluck B (2016) The invisible politics of bitcoin: governance crisis of a decentralized infrastructure. Internet Policy Rev. https://doi.org/10.14763/2016.3.427

DeNardis L (2012) Hidden levels of internet control. Inf Commun Soc 15:720-738. https://doi.org/10.1080/1369118X.2012.659199

Desjardins J (2018) Comparing 25 of the biggest cryptocurrencies I World Economic Forum. In: World Econ. Forum. https://www. weforum.org/agenda/2018/03/comparing-the-25-most-notablecryptocurrencies. Accessed 2 Nov 2018

Dodd N (2018) The social life of bitcoin. Theory Cult Soc 35:35-56. https://doi.org/10.1177/0263276417746464

Drucker P (2017) Blockchain applications in the public sector. In: Deloitte insights. https://www2.deloitte.com/content/dam/Deloi tte/uk/Documents/Innovation/deloitte-uk-blockchain-app-inpublic-sector.pdf. Accessed 15 Feb 2017

edChain (2018) A comparison between 5 major blockchain protocols. In: Medium. https://medium.com/edchain/a-comparison-betwe en-5-major-blockchain-protocols-b8a6a46f8b1f. Accessed 2 Nov 2018

Faife C (2016) Live free or mine: how libertarians fell in love with bitcoin. In: CoinDesk. https://www.coindesk.com/live-free-ormine-how-libertarians-fell-in-love-with-bitcoin/. Accessed 30 Oct 2018

Farmer P (2014) Speculative Tech: the bitcoin legal quagmire \& the need for legal innovation. J Bus Technol Law 9:85

Ferreira JPM, Gonçalves MJA, da Silva AF (2019) A systematic literature review in blockchain: benefits and implications of the technology for business. In: Rocha Á, Adeli H, Reis L, Costanzo $\mathrm{S}$ (eds) New knowledge in information systems and technologies. WorldCIST'19 2019. Advances in intelligent systems and computing, vol 930 . Springer, Cham, pp 405-414

Flore M (2018) How blockchain-based technology is disrupting migrants' remittances: a preliminary assessment. Luxembourg, EUR 29492 EN
Fork A (2018) How blockchain can create a financially inclusive future. In: Mediu.-Hackernoon. https://hackernoon.com/how-block chain-can-create-a-financially-inclusive-future-f7c214b1a4b7. Accessed 31 Oct 2018

Gil de Zúñiga H, Veenstra A, Vraga E, Shah D (2010) Digital democracy: reimagining pathways to political participation. J Inf Technol Polit 7:36-51. https://doi.org/10.1080/19331680903316742

Gleeson-White J (2011) Double entry: how the merchants of venice shaped the modern world - and how their invention could make or break the planet, 1 st edn. Allen \& Unwin, Sydney

Golumbia D (2016) The politics of Bitcoin: software as right-wing extremism, 1st edn. University of Minnesota Press, Forerunners: Ideas, Minneapolis

Golumbia D (2015) Bitcoin as politics: distributed right-wing extremism. Ssrn. https://doi.org/10.2139/ssrn.2589890

Gordon U (2018) Prefigurative politics between ethical practice and absent promise. Polit Stud 66:521-537. https://doi org/10.1177/0032321717722363

Graeber D (2013) The democracy project: a history, a crisis, a movement, 1st edn. Spiegel \& Grau, New York

Graham M (2014) Inequitable distributions in internet geographies: the global south is gaining access, but lags in local content. Innov Technol Gov Glob 9:3-19. https://doi.org/10.1162/inov_a_00212

Grakov A, Chiara (2018) A blockchain platforms comparison. In: VironIT. https://vironit.com/a-blockchain-platforms-comparison I. Accessed 2 Nov 2018

Grant J (2014) On the critique of political imaginaries. Eur J Polit Theory 13:408-426. https://doi.org/10.1177/1474885113519259

Gupta V (2017) A brief history of blockchain. In: Harv. Bus. Rev. https://hbr.org/2017/02/a-brief-history-of-blockchain. Accessed 10 May 2017

Gupta V (2018) How Blockchain will change our global system in the next 10 years I BIC18. In: YouTube. https://www.youtube.com/ watch?v=j-TlmhS17jQ. Accessed 21 Mar 2019

Hackett EJ, Amsterdamska O, Lynch M, Wajcman J (eds) (2008) The handbook of science and technology studies. MIT Press, Cambridge

Hancock M, Vaizey E (2015) Distributed ledger technology: beyond block chain. In: A report by the UK Government Chief Scientific Adviser. UK Government, London, p 88

Harvey D (1990) The condition of postmodernity: an enquiry into the origins of cultural change, 1st edn. Blackwell Publishers Inc, Malden, Massachusetts

Harvey D (2010) RSA ANIMATE: Crises of Capitalism. In: RSAYouTube. $h t t p s: / / w w w . y o u t u b e . c o m / w a t c h ? v=q O P 2 V \_n p 2 c 0$. Accessed 23 Oct 2018

Heller N (2018) Estonia, the Digital Republic. In: New Yorker. https ://www.newyorker.com/magazine/2017/12/18/estonia-the-digit al-republic. Accessed 31 Oct 2018

Herbert J, Litchfield A (2015) A novel method for decentralised peerto-peer software license validation using cryptocurrency blockchain Technology 27-30

Herian R (2018) The politics of blockchain. Law Crit. https://doi. org/10.1007/s10978-018-9223-1

Hjorth L (2017) The Routledge companion to digital ethnography

Hölscher K, Wittmayer JM, Loorbach D (2018) Transition versus transformation: what's the difference? Environ Innov Soc Transit 27:1-3. https://doi.org/10.1016/J.EIST.2017.10.007

Hsu WF (2017) A performative digital ethnography: data, design, and speculation. In: The Routledge companion to digital ethnography. Routledge, pp 66-76

Huckle S, Bhattacharya R, White M, Beloff N (2016) Internet of things, blockchain and shared economy applications. Proc Comput Sci 98:461-466. https://doi.org/10.1016/j.procs.2016.09.074

Ian B (2017) Cryptocurrency might be a path to authoritarianism-the Atlantic. In: Atl. https://www.theatlantic.com/technology/archi 
ve/2017/05/blockchain-of-command/528543/. Accessed 19 June 2018

Jacobovitz O (2016) Blockchain for identity management. Tech Rep Ben-Gurion Univ 1-19

Jeferson E (2018) No, China isn't Black Mirror-social credit scores are more complex and sinister than that. In: New Statesman. https ://www.newstatesman.com/world/asia/2018/04/no-china-isn-tblack-mirror-social-credit-scores-are-more-complex-and-sinis ter. Accessed 1 Nov 2018

Joey (2018) The first community currencies are live!-Colu local network. In: Mediu.-Colu. https://medium.com/colu/the-first -community-currencies-are-live-41e605e7cb9c. Accessed 7 Aug 2019

Karr D (2015) 5 industries radically transformed by the Internet I MarTech. In: Martech. https://martech.zone/industries-changed-bythe-internet/. Accessed 16 Oct 2018

Kelly K (2010) What technology wants, 1st edn. Penguin Random House LLC, New York

Killmeyer J, White M, Chew B (2017) Will blockchain transform the public sector? Deloitte University Press, p 20

Kline RR (2015) Technological determinism. In: International encyclopedia of the social \& behavioral sciences. Elsevier, pp 109-112

König T, Duran E (2016) FairCoin V2 white paper. Faircoin Github, $\mathrm{p} 7$

Kshetri N (2017) Will blockchain emerge as a tool to break the poverty chain in the Global South? Third World Q 38:1710-1732. https ://doi.org/10.1080/01436597.2017.1298438

Kshetri N, Voas J (2018) Blockchain in developing countries. IT Prof. https://doi.org/10.1109/MITP.2018.021921645

Largave K (2017) 8 Cities cracking down on Airbnb-Condé Nast Traveler. In: Condé Nast Travel. https://www.cntraveler.com/ galleries/2016-06-22/places-with-strict-airbnb-laws. Accessed 16 Mar 2018

Lashkov A (2018) Trends and problems: how cryptocurrencies and blockchain will fix the global remittance industry. In: Mediu.Hackernoon. https://hackernoon.com/trends-and-problems-howcryptocurrencies-and-blockchain-will-fix-the-global-remittance -industry-41150c760b2a. Accessed 31 Oct 2018

Liang X, Shetty S, Tosh D et al (2017) ProvChain: a blockchainbased data provenance architecture in cloud environment with enhanced privacy and availability. In: Proceedings-2017 17th IEEE/ACM international symposium on cluster, cloud and grid computing, CCGRID 2017. Institute of Electrical and Electronics Engineers Inc., pp 468-477

Loorbach D, Frantzeskaki N, Avelino F (2017) Sustainability transitions research: transforming science and practice for societal change. Annu Rev Environ Resour 42:599-626. https://doi. org/10.1146/annurev-environ-102014-021340

Lownsbroug H (2017) Uber's practices are morally unacceptable-but a boycott won't help I Hannah Lownsbrough I Opinion I The Guardian. In: Guard. https://www.theguardian.com/commentisf ree/2017/jul/13/uber-practices-company-london-consumersumofus. Accessed 31 Oct 2018

Lu Y (2019) The blockchain: state-of-the-art and research challenges. J Ind Inf Integr 15:80-90

Lubin J, Anderson M, Thomason B (2018) Blockchain for global development. Innov Technol Gov Glob 12:10-17. https://doi. org/10.1162/inov_a_00263

Lynch M (2008) Ideas and perspectives. In: Hackett EJ, Amsterdamska O, Lynch M, Wajcman J (eds) The handbook of science and technology studies, 1st edn. MIT Press, Cambridge, pp 10-26

Mackey TK, Kuo TT, Gummadi B et al (2019) "Fit-for-purpose?"challenges and opportunities for applications of blockchain technology in the future of healthcare. BMC Med. https://doi. org/10.1186/s12916-019-1296-7
Markey-Towler B (2018) Anarchy, blockchain and Utopia: a theory of political-socioeconomic systems organised using blockchain. J Br Blockchain Assoc 1:1-14. https://doi.org/10.31585 /jbba-1-1-(1)2018

McBride KD (2006) Collective dreams: political imagination and community, 1st edn. Pennsylvania State University Press, Pennsylvania

Middlebrook ST, Hughes SJ (2013) Regulating cryptocurrencies in the United States: current issues and future directions. William Mitchell Law Rev 111:813-848. https://doi.org/10.3868/ s050-004-015-0003-8

Min S-J (2010) From the digital divide to the democratic divide: internet skills, political interest, and the second-level digital divide in political internet use. J Inf Technol Polit 7:22-35. https://doi. org/10.1080/19331680903109402

Mouffe C (2005) On the Political, 1st edn. Routledge, London

Mougayar W (2016) The theory of a blockchain circular economy and the future of work. In: Startup Manag. https://startupmanageme nt.org/2016/08/02/the-theory-of-a-blockchain-circular-economyand-the-future-of-work/

Murray D (2014) Prefiguration or actualization? Radical democracy and counter-institution in the occupy movement. Berkeley $\mathbf{J}$ Sociol 1-15

Myers R (2017) Blockchain poetics. In: Catolow R, Garrett M, Jones N, Skinner S (eds) Artists Re: thinking the blockchain, 1st edn. Torque Editions \& Furtherfield, pp 239-251

Norris P (2001) Digital divide: civic engagement, information poverty, and the Internet worldwide, 1st edn. Cambridge University Press, Cambridge, MA

Nowotny H (2014) Engaging with the political imaginaries of science: Near misses and future targets. Public Underst Sci 23:16-20. https://doi.org/10.1177/0963662513476220

O'Dwyer R (2015) The revolution will (not) be decentralised: blockchains. In: Commons transitions blog. http://commonstransiti on.org/the-revolution-will-not-be-decentralised-blockchains/. Accessed 25 Sept 2016

Ølnes S, Ubacht J, Janssen M (2017) Blockchain in government: Benefits and implications of distributed ledger technology for information sharing. Gov Inf Q 34:355-364. https://doi.org/10.1016/j. giq.2017.09.007

Oprunenco A, Akmeemana C (2018) Using blockchain to make land registry more reliable in India I UNDP. In: United Nations Dev. Progr. https://www.undp.org/content/undp/en/home/blog/2018/ Using-blockchain-to-make-land-registry-more-reliable-in-India .html. Accessed 23 Oct 2018

Peters GW, Panayi E (2016) Understanding Modern Banking Ledgers Through Blockchain Technologies: Future of Transaction Processing and Smart Contracts on the Internet of Money. Springer, Cham, pp 239-278

Peyrouzet García-Siñeriz M (2018) In blockchain they trust. Now, power to the people or to the invisible hand? An analysis of the ideological tensions and affinities between crypto-libertarian and crypto-commonist visions, projects and aspirations for the blockchain revolution. Univ Exet-BA Thesis-Philos Econ

Pink S, Horst HA, Postill J et al (2016) Digital Ethnography: Principles and Practice. SAGE Publications, London

Poushter J (2016) Internet access grows worldwide but remains higher in advanced economies. In: Pew Res. Cent. https://www.pewgl obal.org/2016/02/22/internet-access-growing-worldwide-butremains-higher-in-advanced-economies/. Accessed 31 Oct 2018

Radziwill N (2018) Blockchain Revolution: How the Technology Behind Bitcoin is Changing Money, Business, and the World. Qual Manag J 25:64-65. https://doi.org/10.1080/10686 967.2018.1404373

Reijers W, Coeckelbergh M (2016) The Blockchain as a Narrative Technology: Investigating the Social Ontology and Normative 
Configurations of Cryptocurrencies. Philos Technol. https://doi. org/10.1007/s13347-016-0239-x

RightMesh (2018) Putting the power of connectivity into the hands of the people. - The Technology behind RightMesh. https://www. rightmesh.io/technology. Accessed 31 Oct 2018

Risius M, Spohrer K (2017) A Blockchain Research Framework: What We (don't) Know, Where We Go from Here, and How We Will Get There. Bus Inf Syst Eng. https://doi.org/10.1007/s1259 9-017-0506-0

Roubini N (2018) The Big Blockchain Lie by Nouriel Roubini Project Syndicate. In: Proj. Synd. https://www.project-syndi cate.org/commentary/blockchain-big-lie-by-nouriel-roubini2018-10?barrier=accesspaylog. Accessed 5 Dec 2019

Saberi S, Kouhizadeh M, Sarkis J (2018a) Blockchain technologya panacea or pariah for resources conservation and recycling? Resour Conserv Recycl 130:80-81. https://doi.org/10.1016/j. resconrec.2017.11.020

Saberi S, Kouhizadeh M, Sarkis J (2018b) Blockchain technology: a panacea or pariah for resources conservation and recycling? Resour Conserv Recycl 130:80-81. https://doi.org/10.1016/J. RESCONREC.2017.11.020

Schneider N (2017) What to do once you admit that decentralizing everything never seems to work. In: Mediu.-Hackernoon. https ://hackernoon.com/decentralizing-everything-never-seems-towork-2bb0461bd168. Accessed 31 Oct 2018

Scott B (2015) A Dark Knight is better than no Knight at all - King's Review Magazine. In: Kings Rev. https://kingsreview.co.uk/artic les/a-dark-knight-is-better-than-no-knight-at-all/. Accessed 19 Oct 2018

Sivaram V (2018) Blockchain and Energy: We Sifted Hype from Reality So You Don't Have To I Council on Foreign Relations. In: Counc. Foreign Relations. https://www.cfr.org/blog/blockchain-and-energ y-we-sifted-hype-reality-so-you-dont-have. Accessed 23 Oct 2018

Smith MR, Marx L (1994) Does technology drive history?: the dilemma of technological determinism, 1st edn. MIT Press, Malden, Massachusetts

Strate L (2012) If It's neutral, it's not technology. Educ Technol 52:6-9

Sutton M, Johnson C, Gorenflo N (2016) A shareable explainer: what is a platform Co-op? I P2P Foundation. In: P2P Found. https ://blog.p2pfoundation.net/shareable-explainer-platform-coop/2016/09/04. Accessed 31 Oct 2018

Swan M (2015) Blockchain: blueprint for a new economy, 1st edn. O'Reilly Media Inc, Sebastopol, CA

Swartz L (2016) Blockchain dreams: imagining techno-economic alternatives after bitcoin. In: Castells M (ed) Another economy is possible: culture and economy in a time of crisis, 1st edn. Polity, Malden, Massachusetts, pp 82-105

Sylvester-Bradley O (2018) What would a co-op coin ICO look like? In: Open Co-op. https://open.coop/2018/01/25/co-op-coin-icolook-like/. Accessed 1 Nov 2018

Tabora V (2018) The evolution of the internet, from decentralized to centralized. In: Mediu.-Hackernoon. https://hackernoon.com/ the-evolution-of-the-internet-from-decentralized-to-centralize d-3e2fa65898f5. Accessed 23 Oct 2018

Tang Y, Xiong J, Becerril-Arreola R, Iyer L (2019) Blockchain ethics research: a conceptual model. In: SIGMIS-CPR 2019_-proceedings of the 2019 computers and people research conference. Association for Computing Machinery, Inc, pp 43-49

Tapscott D, Tapscott A (2016) Blockchain revolution: how the technology behind bitcoin and other cryptocurrencies is changing the world

Tarasiewicz M, Newman A (2015) Cryptocurrencies as distributed community experiments. Handb Digit Curr. https://doi. org/10.1016/B978-0-12-802117-0.00010-2

Taylor C (2004) Modern social imaginaries, 1st edn. Duke University Press, Durham, NC

Thellmann P (2018) How Blockchain is banking the unbanked. In: Cointelegraph. https://cointelegraph.com/news/how-blockchain -is-banking-the-unbanked. Accessed 31 Oct 2018

Thomason J, Ahmad M, Bronder P et al (2018) Blockchain-powering and empowering the poor in developing countries. In: Marke A (ed) Transforming climate finance and green investment with blockchains, 1st edn. Elsevier, London, pp 137-152

Treiblmaier H (2019) Toward more rigorous blockchain research: recommendations for writing blockchain case studies. Front Blockchain. https://doi.org/10.3389/fbloc.2019.00003

Unruh DR (1980) The nature of social worlds. Pac Sociol Rev 23:271296. https://doi.org/10.2307/1388823

Vigna P, Casey M (2016) The age of cryptocurrency: how bitcoin and the blockchain are challenging the global economic order, 1st edn. St. Martin's Press, New York

Volmar D (2017) Far from the lonely crowd: the trenchant technocynicism of Mr. Robot. Endeavour 41:208-210

Ward KJ (1999) Cyber-ethnography and the emergence of the virtually new community. J Inf Technol 14:95-105. https://doi. org/10.1080/026839699344773

White GRT (2017) Future applications of blockchain in business and management: a Delphi study

Wilson J, Swyngedouw E (2015) The post-political and its discontents: spaces of depoliticisation, spectres of radical politics, 1 st edn. Edinburgh University Press Ltd, Edinburgh

World Economic Forum (2018) Blockchain beyond the hype. In: White Pap. https://www.weforum.org/whitepapers/blockchain-beyon d-the-hype. Accessed 22 Jan 2019

World Population Stats (2018) World internet users statistics and 2018 world population stats. In: Internet World Stats. https://www. internetworldstats.com/stats.htm. Accessed 31 Oct 2018

Yates L (2015) Rethinking prefiguration: alternatives, micropolitics and goals in social movements. Soc Mov Stud 14:1-21. https:// doi.org/10.1080/14742837.2013.870883

Yen D (2017) Blockchain-based FX/treasury solution in Africa. Head of Global Strategic Partnerships, p 29

Zipcoin (2018) Zipco- the true P2P trading \& Remit platforms of the future-Whitepaper v. 1.0.2. Online

Zitter L (2018) To blockchain or not to blockchain: the decision tree with the answer. In: BlockExplorer News. https://blockexplorer. com/news/to-blockchain-or-not-to-blockchain-the-decision-treewith-the-answer/. Accessed 22 Jan 2019

Publisher's Note Springer Nature remains neutral with regard to jurisdictional claims in published maps and institutional affiliations. 